D. R. Clark, Jr.

Acknowledgements: We thank J. L. Soriguer and C. Melgarejo for making our field work easier. C. M. Herrera critized a draft of this manuscript. During the writing of this note the authors were assisted by a grant from the Fundacion March (to J. A. A.) and a grant from Plan Formación Personal Investigador (to R. C. S.).

\title{
REFERENCES
}

A lvarez F. \& Hiraldo F., 1974: Estructura de las galerias de nidificación del Abejaruco (Merops apiaster) en Doñana. Doñana Acta Vert., 1: 61-67. Soriguer R. C. \& A mat J. A., in press: Ecological and evolutionary relationships between the Mediterranean Vole (Pitymys duodecimcostatus) and geophytes in the western Mediterranean Basin. J. Mammal. (submitted).

Accepted, February 15, 1980.

\section{Canine Tooth Wear in Captive Little Brown Bats}

\author{
STARCIA KŁOW U NOCKOW MYOTIS L. LUCIFUGUS W NIEWOLI
}

Donald R. CLARK, Jr.

Clark D. R., Jr., 1980: Canine tooth wear in captive little brown bats. Acta theriol., 25, 21: 270-273 [With 1 Fig.]

Upper canine teeth of little brown bats Myotis lucifugus lucifugus (Le Conte, 1831) held in stainless steel wire mesh cages underwent severe wear which exceeded that observed previously in caged big brown bats Eptesicus fuscus fuscus (Palisot de Beauvois, 1796). This suggests a relationship between amount of wear and size of the caged bats with damage increasing as size decreases. Rapid wear of canine teeth by little brown bats resembled that observed in big brown bats in that it was limited to the first 2 weeks of captivity. This result indicates a universal interval for acclimation to cage conditions among vespertilionid bats. Dietary toxicants $\mathrm{DDE}$ and $\mathrm{PCB}$ did not affect the extent of wear. If bats are to be released to the wild, confinement in wire mesh cages should be avoided.

[U.S. Fish and Wildlife Service, Patuxent Wildlife Research Center, Laurel, Maryland 20811, U.S.A.].

\section{INTRODUCTION}

Upper canine teeth of caged big brown bats Eptesicus fuscus fuscus (Palisot de Beauvois, 1796) underwent severe wear during captivity (C la rk, 1976). The purpose of the present study is to quantify wear that occurred among captive little brown bats Myotis lucifugus lucifugus (Le Conte, 1831) and compare it to that observed in big brown bats.

\section{MATERIALS AND METHODS}

On 6 July 1976, 51 adult female little brown bats were captured in the attic of North East Methodist Church in North East, Cecil County, Maryland, U.S.A. The bats were collected for a toxicological experiment. Five bats, two that were injured during capture and three others chosen at random, were frozen without being caged. The other 46 bats were individually caged in stainless steel wire 
mesh cáges $(18 \times 22 \times 37 \mathrm{~cm})$ and fed mealworms for 1 week. During this week three bats died, perhaps of starvation, and two others were frozen because they did not eat well and lost considerable weight. The remaining 41 bats were dividéd randomly into three groups: a group of seven control bats continued to receive uncontaminated mealworms, and two groups of 17 bats each began receiving mealworms containing either DDE (principal breakdown product of DDT) or PCB (polychlorinated biphenyl, Aroclor 1260). After 40 days of dosage followed by 14 days of food restriction, all bats had died. Food restriction was used to mobilize $\mathrm{DDE}$ and $\mathrm{PCB}$ stored in fat. Chemical analyses of these bats' brains will define lethal levels and thereby allow evaluation of levels in bats found dead in the field.
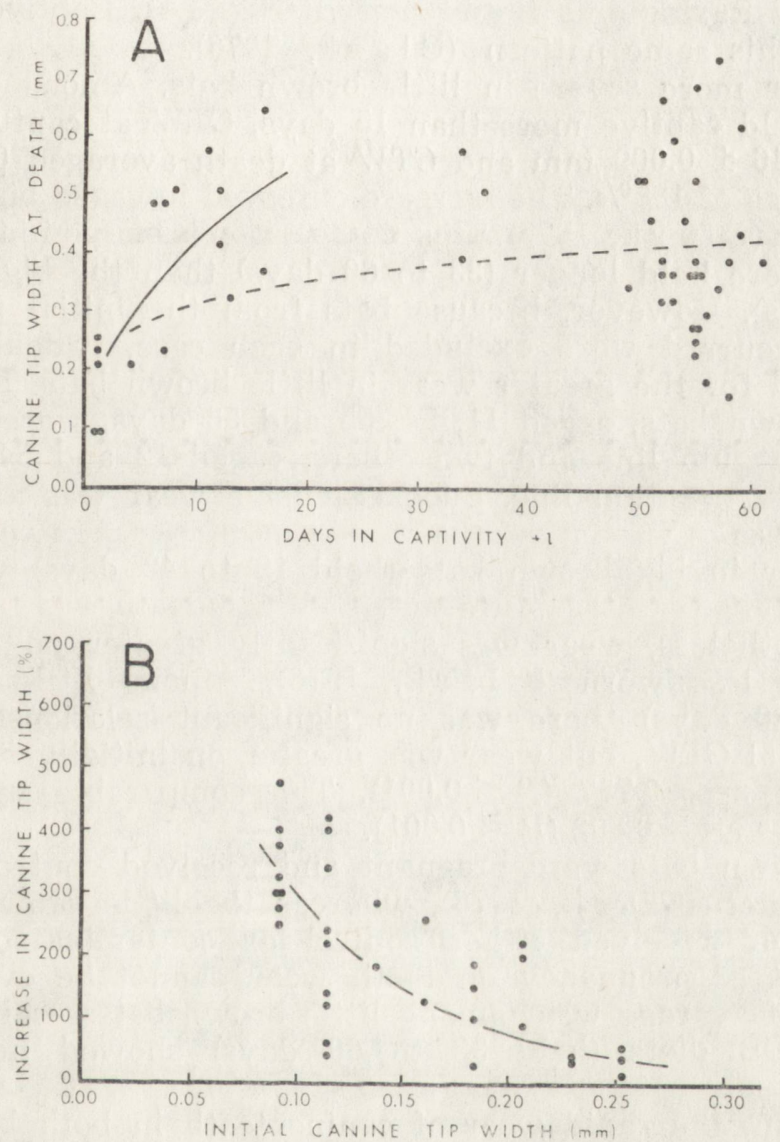

Fig. 1. (A) Canine tip width at death versus days in captivity for 51 female little brown bats. Dashed regression line $\left(\log _{10} Y=0.175 \log _{10} X+\log _{10} 0.208\right)$ represents all bats; solid line $\left(\log _{10} \mathrm{Y}=0.420 \log _{10} \mathrm{X}+\log _{10} 0.159\right)$ represent bats that died during their first 15 days of captivity. Because the number of days was zero in some cases, the constant 1 was added to each value to allow conversion to logs. (B) Percent increase in canine tip width in relation to canine tip width at capture for 35 bats held captive 33 to 60 days $\left(\log _{10} \mathrm{Y}=\log _{10} 1159-13.6 \mathrm{X}\right)$.

The occlusal tip width of the left upper canine (canine tip width, CTW) was ineasured with an ocular micrometer in a $30 \times$ dissecting microscope. CTWs of live bats were measured with the aid of the inhalant anesthetic Metofane (PitmanMoore, Inc., Fort Washington, Pennsylvania, U.S.A.) before they were placed in čóges, 
This study utilized the same laboratory, cages, tooth measuring equipment, ar $\mathrm{d}$ bat maintenance techniques that were used to study big brown bats ( $\mathrm{Clark}$, 1976).

\section{RESULTS AND DISCUSSION}

CTW was correlated with days of captivity for the entire study period $(1=0.495, P<0.001, N=51)$, but the relationship was stronger during the first 15 days $(r=0.792, P<0.001, N=16)$; apparently most of the wear occurred during this initial period (Fig. 1A). Captive big brown bats showed this same pattern (C $1 \mathrm{ark}, 1976)$.

Canine wear more severe in little brown bats. Among the 35 little brown bats held captive more than 15 days, CTW at capture averaged ( \pm 1 S.E.) $0.146 \pm 0.009 \mathrm{~mm}$ and $C T W$ at death averaged $0.421 \pm 0.024$ $\mathrm{mm}$, an increase of $188 \%$. The increase observed in caged big brown bats was only $82 \%$ ( $\mathrm{Cl}$ a r k, 1976). This comparison is biased in that the little brown bats were held longer (33 to 60 days) than the big brown bats (19 to 42 days). However, because bats from the initial period when most wear occurred were excluded in each case, I doubt that this bias accounted for the greater wear in little brown bats. Furthermore, four little brown bats, caged 11, 54, 55 and 58 days, wore their upper canines to the gum line and two others, caged 12 and 54 days, wore them nearly to the gum line. Such extensive wear was absent among big brown bats.

Canine wear in big brown bats (held 19 to 42 days) was uniform enough so that $C T W$ at capture and $C T W$ at death were weakly correlated; nevertheless, wear was significantly greater on canines that were initially less worn ( $\mathrm{Cl} \mathrm{a} \mathrm{rk}, 1976)$. Among little brown bats (held 33 to 60 days) there was no significant relationship between initial and final $C T W$, but wear was greater on initially sharper teeth (Fig. 1B) and $r=-0.737(P<0.001)$. The comparable value for big brown bats was $r=-0.802(P<0.001)$.

The big brown bats were pregnant and received control (= contaminant-free) diet ( $\mathrm{Cl} \mathrm{a} \mathrm{r} \mathrm{k,} \mathrm{1976),} \mathrm{whereas} \mathrm{the} \mathrm{little} \mathrm{brown} \mathrm{bats} \mathrm{were}$ postpartum and received either control or contaminated diets. The possible effect of pregnancy on tooth wear cannot be evaluated, but comparisons of average wear among dittle brown bats receiving control, $\mathrm{DDE}$, and $\mathrm{PCB}$ diets (held 33 to 60 days) showed no significant differences.

In conclusion, the rapid wear of canine teeth in both big and little brown bats was limited to the bats' first 2 weeks in captivity. This suggests a universal interval for acclimation to cage conditions among bats of the family Vespertilionidae. Knowledge of this interval could be useful for laboratory experiments that require acclimated bats. These results also suggest that the smaller the bat species the more severe will be the damage to its teeth. Furthermore, CTW values from bats held captive in this way would not be comparable to those of free-living individuals in the same population. Because wear is most rapid initially, any period of captivity might alter $C T W s$ and affect conclusions regarding age, or relative age, based on them. Many studies have thus used CTW data; for a review and discussion see B a a gø e (1977). Finally, if bats 
are to be released to the wild, severe tooth wear could reduce their life expectancies; therefore, wire mesh containers should be avoided.

Acknowledgements: I thank R. O. Wallace for providing access to the bat colony. For assistance in catching and maintaining the bats, I thank J. A. Dowdy, G. G. Chasko, and P. H. Brockdorff. Finally, I thank E. Dustman for his critical review of the manuscript.

\title{
REFERENCES
}

B a a g $ø$ e H. J., 1977: Age determination of bats (Chiroptera). Vidensk Meddr dansk naturh. Foren., 140: 53-92. Clark D. R., Jr., 1976: Canine tooth wear in captive big brown bats (Eptesicus fuscus). J. Mammal., 57: 778-780.

Accepted, February 20, 1980.

\section{The Effect of $\mid$ Litter Size on Body Weight of Young Rats}

\author{
WPŁYW WIELKOSCI MIOTU NA CIEZAR CIAŁA MŁODYCH SZCZUROW
}

\section{Ewa T. MYSTKOWSKA ${ }^{1}$}

Mystkowska E. T., 1980: The effect of litter size on body weight of young rats. Acta theriol., 25, 21:273-275 [With 1 Table]

A comparison was made of the body weight of embryos 20 days old and newborn rats from litters consisted of $9-10$ young and 13-14 young. Body weight of embryos does not differ significantly and in newborn individuals the difference is significant.

[Inst. Gynaecology \& Obstetrics, Medical Academy, Karowa 2, 00-315 Warszawa].

\section{INTRODUCTION}

It is generally considered that the weight of young mammals depends upon their numbers in the litter, the more numerous the litter, the smaller the weight of the newborn animals ( $\mathrm{G}$ a t e s, 1925; M c L a r e n, 1965). The purpose of the present study was to ascertain at which stage of intrauterine growth such differentiation in weight takes place. To explain this question body weight of 20 day-old embryos and newborn animals from smaller litters (9-10 young per litter) and larger litters (13-14 young per litter) were compared.

\section{MATERIALS AND METHODS}

The material consisted of 199 20-day old ambryos and placentae, and 204 newborn young of the Wistar random bred rats. Female - mothers were fed on the standard granulated feed and supplied with tapwater. The period of light was controlled - 14 hours light per 24 hours. As from the 20 th day of gestation females about to bear young were kept singly in separate cages.

The embryos were removed from the uterus on the 20th day of gestation between $10^{00}$ and $13^{\text {ro }}$. The first day of preonancy was taken the day in which spermatozoa in vaginal smear were found. The embryos were removed from the foetal membranes, separated from the umbilical cord and the embryos and placentae weighed.

1 Present address: Inst. Biostructure, Medical Academy, Chałubińskiego 5, 02-004 Warszawa. 